\title{
Diyabetik ve Non-Diyabetik Farelerin Midesinin Fundus Bölgesinde Hepatosit Büyüme Faktörü (HGF)’nün İmmunohistokimyasal Lokalizasyonu*
}

\author{
Serap iLHAN AKSU ${ }^{1 \mathrm{a} \otimes}$, Turgay DEPREM ${ }^{1 \mathrm{~b}}$
}

1. Kafkas Üniversitesi, Veteriner Fakültesi, Histoloji ve Embriyoloji Anabilim Dalı, Kars, TÜRKiYE. ORCID: 0000-0003-3100-498Xa, 0000-0002-5523-8150 b

\begin{tabular}{|c|c|c|}
\hline $\begin{array}{c}\text { Geliş Tarihi/Received } \\
12.02 .2021\end{array}$ & $\begin{array}{c}\text { Kabul Tarihi/Accepted } \\
27.07 .2021 \\
\end{array}$ & $\begin{array}{c}\text { Yayın Tarihi/Published } \\
30.12 .2021\end{array}$ \\
\hline $\begin{array}{l}\text { Bu makaleye atıfta bulunmak iç } \\
\text { İlhan Aksu S, Deprem T: Diyabe } \\
\text { (HGF)'nün İmmunohistokimyas } \\
\text { 10.17094/ataunivbd.879099 }\end{array}$ & $\begin{array}{l}\text { article: } \\
\text { abetik Farelerin Midesini } \\
\text { h. Atatürk Üniversitesi }\end{array}$ & $\begin{array}{l}\text { inde Hepatosit Büyüme Faktörü } \\
. \text { 16(3): 251-258, 2021. DOI: }\end{array}$ \\
\hline
\end{tabular}

Öz: Çalışmamızda, diyabetik ve non-diyabetik farelerin midelerinin fundus bölgesinde meydana gelen yapısal değişiklikleri histolojik olarak incelemek ve Hepatosit Büyüme Faktörü (HGF)'nün midedeki immunohistokimyasal dağılımını belirlemek amaçlanmıştır. Çalışmada, 45 adet swiss albino fare, kontrol, sham ve diyabetik olarak üç gruba ayrıldı. Diyabet oluşturulması için $100 \mathrm{mg} / \mathrm{kg}$ STZ intraperitoneal (IP) uygulaması ile yapıdı. $200 \mathrm{mg} / \mathrm{dl}$ 'nin üzerinde kan glikoz düzeyi olan fareler diyabetli olarak kabul edildi. Deneklerin mide dokuları 3., 15. ve 30. günlerde alındı. Mide dokusunun fundus bölgesinin histolojik yapısını incelemek için alınan kesitlere H\&E boyaması yapıldı. HGF'nin immunoreaktivitesini belirlemek amacıyla AvidinBiotin-Peroksidaz Kompleks (ABC) metodu uygulandı. Çalışmada diyabetik grupta diğer gruplara göre canlı ağırlıkta azalma olduğu belirlendi. Diyabetik ratların mide dokusunun histolojik yapısında kontrol grubuna göre bir farklılık görülmedi. Diyabetik, kontrol ve sham gruplarında HGF'nin benzer alanlarda immunolokalizasyon gösterdiği saptandı. HGF immunreaktivitesinin diyabetik grupta kontrol ve sham gruplarına göre daha zayıf bir reaksiyon verdiği tespit edildi. HGF, diyabet ve midenin fundus bölgesinin ilişkisini açıklayan immunohistokimyasal bir araştırmaya rastlanılmadığı için yaptığımız çalışmanın bu ilişkiyi açıklamasına yardımcı olacağını ve bu alanda yapılacak yeni çalışmalara yol göstereceğini düşünmekteyiz.

Anahtar Kelimeler: Diyabet, Fundus, HGF, İmmunohistokimya.

\section{Immunohistochemical Localization of Hepatocyte Growth Factor (HGF) in the Fundus Area of the Stomach of Diabetic and Non-Diabetic Mice}

\begin{abstract}
Our study has been conducted in order to histologically analyze the morphologic changes that occur in the fundus area of the stomachs of diabetic and non-diabetic mice and designate the immunohistochemical distribution of the hepatocyte growth factor (HGF) in the stomach. Forty-five Swiss albino mice have been divided into control, sham, and diabetic groups for the study. Streptozotocin at the dose of $100 \mathrm{mg} / \mathrm{kg}$ has been administered intraperitoneally (IP) to the end of inducing diabetes. Mice with blood glucose levels higher than $200 \mathrm{mg} / \mathrm{dl}$ have been deemed diabetic. Stomach tissues of the specimens were collected on the 3rd, 15th, and 30th days. H\&E stain has been performed on the sections in order to examine the histological structure of the fundus area of the stomach. The Avidin-Biotin-Peroxidase Complex (ABC) method has been performed in order to determine the immunoreactivity of HGF. In the study, it has been found that bodyweight had been decreased in the diabetic group compared to other groups. There was no difference in the histological structure of the stomach tissue of diabetic rats compared to the control group. HGF has been observed to demonstrate immunolocalization on similar areas in the diabetic, control, and sham groups. HGF immunoreactivity has been found to react in a milder way in the diabetic group compared to other groups. We think that the study we have conducted will usher in future studies in this field and help explain the relationship between diabetes and the fundus area of the stomach since no immunohistochemical study explaining this relationship has been found in the literature.
\end{abstract}

Keywords: Diabetes, Fundus, HGF, Immunohistochemistry.

\footnotetext{
Serap Illhan Aksu

Kafkas Üniversitesi, Veteriner Fakültesi, Histoloji ve Embriyoloji Anabilim Dalı, Kars, TÜRKiYE.

e-posta: serapilhan01@gmail.com

*Bu çalışma ‘Diyabetik ve Non-Diyabetik Farelerin Midesinin Fundus Bölgesinde Hepatosit Büyüme Faktörü (HGF)'nün

Immunohistokimyasal Lokalizasyonu' adlı tezden üretilmiştir.
} 
Giriş

D iyabetes Mellitus (DM), metabolizma bozukluğunun şiddetine bağı olarak asemptomatik veya polidipsi, poliüri, polifaji, kilo kaybı ve güçsüzlük gibi klinik semptomlarla karakterize olan, birçok organ ve sistemi etkileyen bir hastalıktır (1). Hepatosit büyüme faktörü (HGF) ilk kez (1980'li yıllarda) hepatositlerin büyümesini sağlayan bir faktör olarak tespit edilmiştir. Sonrasında HGF'nin pankreas $\beta$ hücreleri, akciğer ve böbrek gibi çeşitli organların epitel hücrelerinde, fibroblast, makrofaj, düz kas hücreleri gibi mezengial hücrelerde üretilen pleiotropik bir sitokin olduğu anlaşılmıştır (2). HGF, çeşitli hücre tiplerinde migrasyon, proliferasyon ve morfolojik değişiklikleri uyaran bir salgı proteinidir. (3). HGF, $\alpha$ ve $\beta$ zincirlerini içeren tek zincir prekürsör olarak sentezlenir. HGF reseptörü c-met başlıca vasküler endotel hücreler, lenfatik endotel hücreler, nöral hücreler, hepatositler, hematopoetik hücreler ve perisitleri içine alan çeşitli epitel hücrelerinde bulunur (4). HGF'nin pankreas beta hücrelerinde insülin üretimini ve mitogenezisi uyardığı bildirilmiştir. HGF pankreasın alfa hücrelerin de üretilir ve hipergliseminin önlenmesini, beta hücrelerinde insülin üretimini düzenler. HGF c-met sistemleri bulundukları dokuların sadece tamirlerinde değil metabolik homeostazide de etkili olduğu ve HGF pankreas beta hücrelerinde insülin üretimini ve mitogenezisi uyardığı bildirilmiştir (5).

Organ ve sistemleri etkileyen diyabetin mide ve bağırsak sistemini etkileyerek sindirim sisteminde çeşitli rahatsızlıkları tetiklediği düşünülmektedir $(6,7)$. Yapılan birçok çalışmada HGF'nin diyabette biyolojik bir belirteç olarak kullanılabileceği belirtilmektedir (8-10). Oliveira ve arkadaşları (11) yaptıkları araştırmada güncel literatür ve bilgilere dayanarak, HGF'nin metabolik bozukluklarda merkezi bir rol oynadığını, HGF seviyesinin hastalık durumu/ilerlemesi açısından belirteç olarak kullanılabileceğini ve c-Met sinyal yolağı üzerinden seviyesinin düzenlenip diyabetin tedavisinde kullanılabileceğini belirtmişlerdir.
Diyabetes mellitus'un midedeki etkileri, HGF'nin ise hücreler üzerindeki onarıcl, doku farklılaşmasını sağlayııı yetenekleri düşünülerek; çalışmamızda diyabet oluşturulmuş farelerin mide dokusunda HGF immunoreaktivitesinin lokalizasyonu incelendi.

\section{MATERYAL ve METOT}

Deney hayvanları Erzurum Veteriner Kontrol ve Araştırma Enstitüsü Deney Hayvanları Enstitüsünden temin edildi. Farelerde yapılan uygulamalar için Kafkas Üniversitesi Veteriner Fakültesi KAÜHADYEK/2014-008 kodlu Etik Kurulu onayı alındı.

\section{Deney Hayvanları ve Diyabet Oluşturulması}

45 adet swiss albino fare (ortalama 8-12 haftalık) kontrol $(n=15)$, sham $(n=15)$ ve deneme $(n=15)$ olarak 3 gruba ayrıldı. Deney hayvanları standart fare kafeslerinde, $22 \pm 2{ }^{\circ} \mathrm{C}$ ISI ve $\% 50 \pm 5$ nem oranı olan ve 12 saat ışık ile 12 saat karanlık olan standart bir ortamda tutuldu. Diyabetik grubuna $\mathrm{pH}$ 4.5'deki $0.1 \mathrm{M}$ sitrat tamponunda çözdürülen streptozotosin (STZ) (Sigma S0130-100 MG) 100 $\mathrm{mg} / \mathrm{kg}$ dozda intraperitoneal uygulandı. Sham grubuna $\mathrm{pH} \quad 4.5^{\prime}$ deki $0.1 \mathrm{M}$ sitrat tamponu uygulanırken kontrol grubuna herhangi bir uygulama yapılmadı. Diyabetik grubuna STZ uygulamasından 72 saat sonra 8 saatlik açlık sonrası farelerden alınan kanda glukometre ile $200 \mathrm{mg} / \mathrm{dl}$ 'nin üzerinde kan glikoz düzeyi olanlar diyabetli olarak kabul edildi (12).

\section{Histolojik İnceleme}

Farelerin canlı ağırlıkları, deneye ilk başlangıc zamanı 0 kabul edilerek, 0., 3., 15. ve 30. günlerde 8 saatlik açlık sonrası tartıldı. Farelerden doku örnekleri eter anestezisi altında servikal dislokasyon sonrası 3., 15. ve 30. günlerde alındı. Alınan doku örnekleri $\% 10^{\prime}$ luk formoldehit solüsyonunda içerisinde tespit edildikten sonra rutin histolojik doku takip prosedürü uygulanarak parafine bloklandı. Hazırlanan parafin bloklardan $5 \mu \mathrm{m}$ kalınlığında kesitler alındı. Histolojik 
incelemeler için alınan örnek kesitlerine Hematoksilen\&Eosin (H\&E) boyaması uygulandı (13). Örneklerin diğer bir kısmı ise immunohistokimyasal incelemelerde kullanıldı.

\section{İmmunohistokimyasal İnceleme}

HGF'nin glandular midedeki immunolokalizasyonunu incelemek için AvidinBiotin-Peroksidaz kompleks (ABC) tekniği (14) uygulandı. Doku örneklerinden hazırlanan kesitler oda sıcaklığında anti-HGF (Santa Cruz: sc7949) (1:400) ile 1 saat süreyle inkübasyona bırakıldı. Ardından PBS ile yıkama sonrası kesitlere sekonder antikor (Biontinylated Goat Anti-Rabbit (Lab. Vision, 510.991.2800)) ilave edilerek $30 \mathrm{dk}$ oda ISIsında bekletildi. Fosfat buffer salinde yıkanan kesitlere streptavidin horse radish peroksidaz ilave edilerek oda sıcaklığında $15 \mathrm{dk}$ tutuldu. Sonra PBS ile yıkanan kesitlere kromojen uygulaması için Diaminobenzidinhidrojen peroksidaz (DAB- H2O2) tekniği (15) uygulandı. Çekirdek boyaması için Mayer's Hematoksilen kullanıldı. Ardından preparatlar ışık mikroskobunda (Olympus Bx51, Japan) incelenerek fotoğraflandı.

\section{İstatistiksel Analiz}

Toplanan veriler SPSS 16.0 programında OneWay ANOVA testi ve ardından çoklu karşılaştırma testlerinden Duncan testiyle analiz edilerek, grupların ortalama değerleri arasındaki farkların önem dereceleri $\mathrm{P}<0.05$ değeri önemli kabul edilerek belirlendi.

\section{BULGULAR}

\section{Kan-Glikoz ve Canlı Ağırlık Bulguları}

Kontrol ve sham gruplarında her grubun kendi içerisinde canlı ağırlık ortalaması yönü ile anlamlı bir fark gözlenmedi. Diyabetik grubunda zamana bağlı olarak canlı ağırlıkta azalma olduğu ve bununda istatistiksel açıdan anlamlı $(P<0.05)$ bir fark sergilediği gözlendi (Tablo 1).

Tablo 1: Grupların canlı ağırlık istatistiksel bulguları $(P<0.05)$.

Table 1: Statistical analysis of body weight between groups $(\mathrm{P}<0.05)$.

\begin{tabular}{|c|c|c|c|c|}
\hline $\begin{array}{l}\text { Canlı } \\
\text { Ağırlık }\end{array}$ & $\mathrm{n}$ & Kontrol & SHAM & Diyabetik \\
\hline 0. gün & 15 & $38.02 \pm 1.78^{a}$ & $38.62 \pm 2.79^{a}$ & $40.54 \pm 1.67^{a}$ \\
\hline 3. gün & 15 & $38.19 \pm 1.88^{a}$ & $37.18 \pm 2.38^{a}$ & $38.50 \pm 1.15^{a}$ \\
\hline 15. gün & 10 & $37.93 \pm 2.02^{\mathrm{a}}$ & $37.77 \pm 1.87^{a}$ & $29.32 \pm 2.08^{b}$ \\
\hline 30. gün & 5 & $36.09 \pm 1.69^{a}$ & $37.20 \pm 2.34^{a}$ & $27.60 \pm 1.76^{b}$ \\
\hline
\end{tabular}
kontrol ve sham grubuna göre istatistiksel yönde anlamlı $(P<0.05)$ düzeyde yüksek olduğu görüldü (Tablo 2).

Tablo 2: Grupların kan-glikoz değerleri istatistiksel bulguları $(\mathrm{P}<0.05)$.

Table 2: Statistical analysis of blood-glucose level between groups $(P<0.05)$.

\begin{tabular}{|c|c|c|c|c|}
\hline $\begin{array}{l}\text { Kan } \\
\text { Glikoz }\end{array}$ & $\mathrm{n}$ & Kontrol & Sham & Diyabetik \\
\hline 0. gün & 15 & $115.67 \pm 4.87^{a}$ & $107.27 \pm 7.65^{a}$ & $110.27 \pm 4.25^{a}$ \\
\hline 3. gün & 15 & $121.93 \pm 6.03^{b}$ & $120.07 \pm 4.68^{b}$ & $301.93 \pm 17.20^{a}$ \\
\hline 15. gün & 10 & $120.20 \pm 5.87^{b}$ & $118.10 \pm 5.03^{b}$ & $332.50 \pm 13.69^{a}$ \\
\hline 30. gün & 5 & $122.60 \pm 7.30^{b}$ & $120.80 \pm 8.11^{b}$ & $394.60 \pm 26.06$ \\
\hline
\end{tabular}

\section{Histolojik Bulgular}

Yapılan ışık mikroskobik incelemelerde, fundusun histolojik yapısının kontrol ve diyabetik gruplarında benzer olduğu ve farklılık bulunmadığı görüldü (Şekil 1-A,B). Ayrıca grupların kendi içerisinde 3., 15. ve 30. günler yönü ile histolojik olarak herhangi bir farklılık gözlenmedi. Gruplar arasında tunika mukoza, tunika submukoza, tunika muskularis ve tunika seroza katmanlarında histolojik olarak bir farklılık olmadığı gözlendi (Şekil 1-A,B,C). 

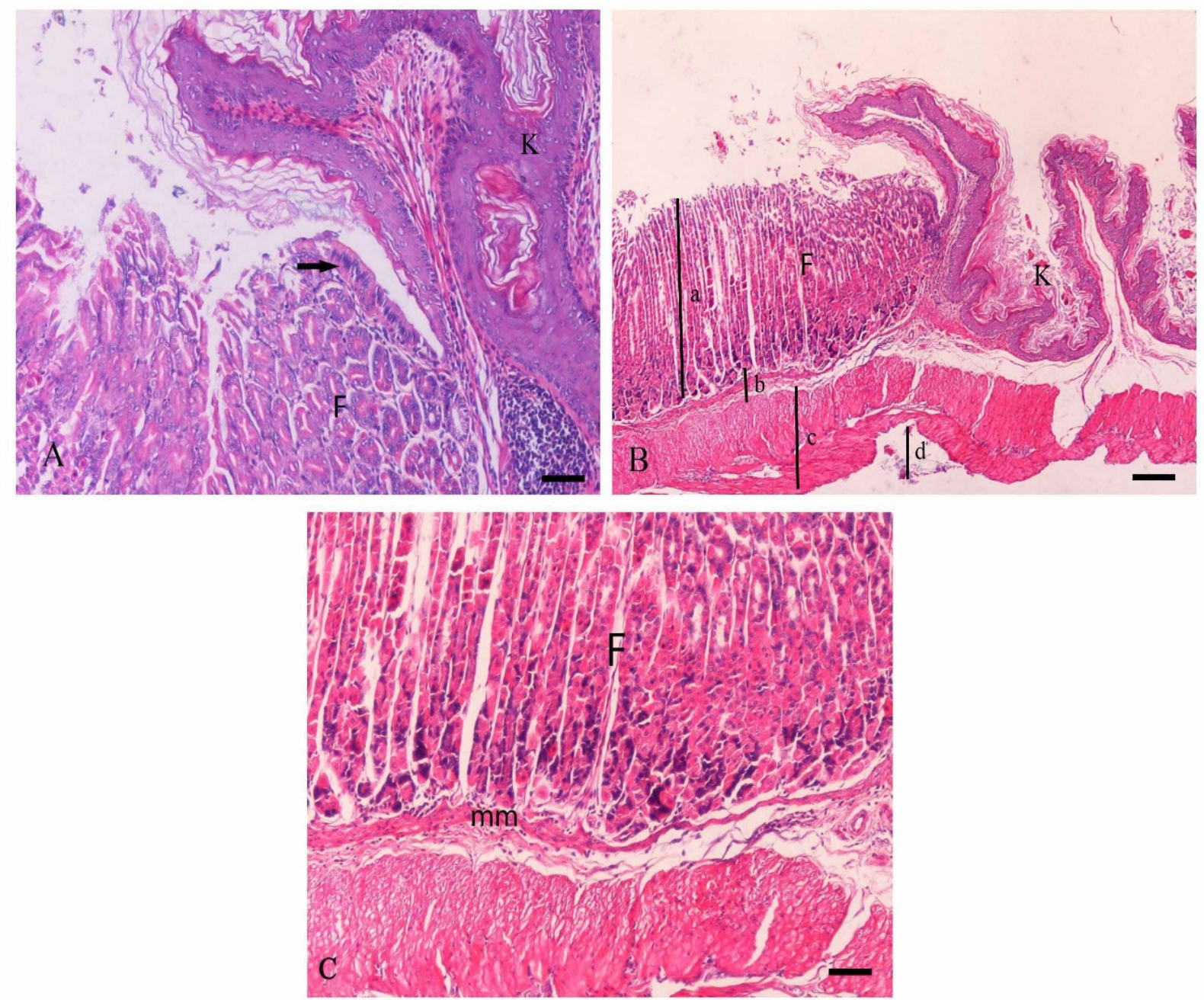

Şekil 1. A: Kontrol grubu mide dokusu histolojik görünümü Bar: $200 \mu \mathrm{m}$. B: Diyabetik grubu mide dokusu histolojik

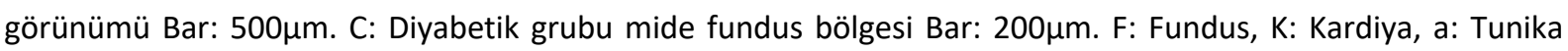
mukoza, b: Tunika submukoza, c: Tunika muskularis, d: Tunika seroza, Ok: Tek katlı prizmatik epitel yapısı, mm: muskuler mukoza. H\&E boyama.

Figure 1. A: General view of stomach tissue in the control group Bar: $200 \mu \mathrm{m}$. B: General view of stomach tissue

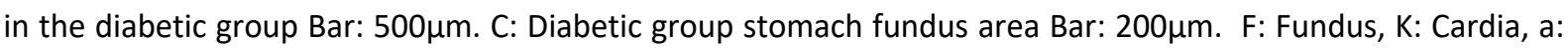
Tunica mucosa, b: Tunica submucosa, c: Tunica muscularis, d: Tunica serosa, Arrow: Single layer prismatic epithelial structure, mm: muscular mucosa, H\&E staining.

\section{İmmunohistokimyasal Bulgular}

Tüm gruplarda 3., 15. ve 30. günlere ait midenin fundus bölgesi HGF immunoreaktivitesi yönünden incelendi. Diyabetik, kontrol ve sham gruplarının tümünde HGF'nin benzer alanlarda immunolokalizasyon gösterdiği belirlendi. HGF immunoreaktivitesinin, propria katmanında, özellikle de kriptlerin çevrelediği taban bölgedeki bağ dokuda yoğun olduğu gözlendi (Şekil 2-A).
Yine submukoza katmanındaki bağ doku hücrelerinin genelinde HGF immunoreaktivitesi gözlendi. Ayrıca sirküler ve longitudinal seyirli kas tabakalarının ara bölgesindeki bağ dokuda yer yer HGF immunoreaktivitesi olduğu belirlendi. Endotel hücrelerde ve bağ doku alanlarındaki HGF immunoreaktivitesi benzer düzeyde görüldü. HGF immunoreaktivitesinin gruplar içerisinde günlere göre benzer olduğu tespit edildi. 

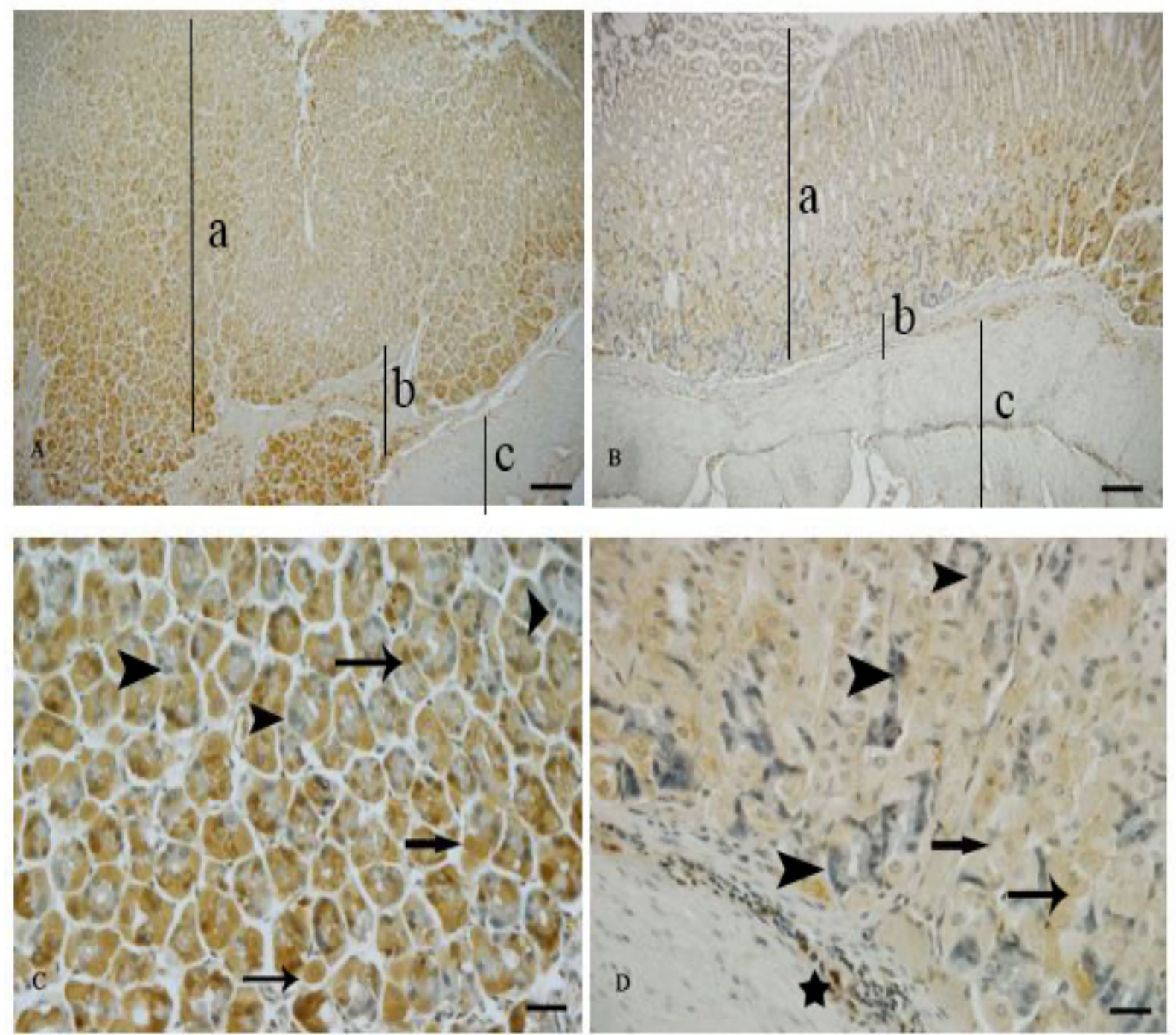

Şekil 2. A: Kontrol grubu HGF immunoreaktivitesi genel görünümü Bar: $200 \mu m$. B: Diyabetik grup HGF immunoreaktivitesi genel görünümü, Bar: $200 \mu \mathrm{m}$. C: Kontrol grubu fundus bölgesi HGF immunoreaktivitesi

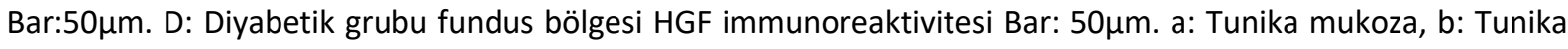
submukoza, c: Tunika muskularis, Oklar: Pariyetal hücre Okbaşları: Prensipal hücreler, Yıldız: Damar endoteli.

Figure 2. A: General view of HGF immunoreactivity in the control group Bar: $200 \mu \mathrm{m}$. B: General view of HGF immunoreactivity in the diabetic group, Bar: $200 \mu \mathrm{m}$. C: HGF immunoreactivity in the control group fundus area Bar: $50 \mu \mathrm{m}$. D: HGF immunoreactivity in the diabetic group fundus area, Bar: $50 \mu \mathrm{m}$. a: Tunica mucosa, b: Tunica submucosa, c: Tunica muscularis, Arrows: Parietal cell, Arrowheads: Chief cell, Star: Vascular endothelium.

Prensipal hücrelerde bölgesel olarak az sayıda HGF immunoreaktivitesi gözlenirken pariyatel hücrelerde ise HGF immunoreaktivitesi değişik düzeylerde ancak bütün hücrelerde olduğu belirlendi (Şekil 2-C,D). Bu immunoreaktivitenin pariyetal ve prensipal hücrelerde sitoplazmik olduğu gözlendi. HGF immunoreaktivitesinin prensipal hücrelere göre pariyetal hücrelerde daha yoğun olduğu tespit edildi (Şekil 2-C). HGF immunoreaktivitesinin pariyetal ve prensipal hücrelerinde kontrol ve sham gruplarında benzer, diyabetik grubunda ise az yoğun olduğu gözlemlendi (Şekil 2-A,B) (Tablo 3). Bu immunoreaktivitelerin günler içerisinde bir fark sergilemediği gözlendi. 
Tablo 3. Gruplar içerisinde HGF immunoreaktivitesinin derecelendirme sonuçları

Table 3. Grading results of HGF immunoreactivity within groups.

\begin{tabular}{llll}
\hline $\begin{array}{llll}\text { Immunoreaktivite } \\
\text { Alanları }\end{array}$ & Kontrol & Sham & Diyabetik \\
\hline Bağdoku Alanları & +++ & +++ & +++ \\
Pariyetal Hücreler & +++ & +++ & + \\
Prensipal Hücreler & + & + & - \\
Endotel Hücreleri & ++ & +++ & +++ \\
\hline$=$ Immunoreaktivite yok, += Az yoğun, ++= Orta derecede yoğun, $+++=$ Çok yoğun
\end{tabular}

Ayrıca mide dokusunun fundus bölümünde tunika mukoza, tunika submukoza ve tunika muskularis alanlarında bulunan kan damarı endotelinde de immunoreaktivite tespit edildi. Bunlara ilaveten kriptleri oluşturan hücreler arasında fibroblast olduğu düşünülen yer yer HGF pozitif hücreler tespit edildi.

\section{TARTIŞMA ve SONUÇ}

Araştırmacılar $(16,17)$ diyabetin canlı ağırlıkta azalmaya neden olduğunu bildirmişlerdir. Bizim yaptığımız çalışmada da diyabetli farelerin vücut ağırığının azaldığı tespit edildi.

Diyabetes Mellitusun çok çeşitli patolojik durumlar gösterdiği ve uzun süreli diyabetin gastrointestinal sisteme zarar verdiği belirtilmiştir $(18,19)$. Ayrıca kronik diyabetli hastalarda, özellikle gastrik salınımın ve motilitenin azalması gastrointestinal fonksiyonlarda sık görülen önemli değişikler olarak bildirilmiştir $(20,21)$. Gastrointestinal semptomların Diyabetes Mellitus'ta oldukça yaygın olduğu ve genellikle otonomik nöropatiye dayandırıldığı belirtilmiştir $(22,23)$. Diyabet komplikasyonlarının patofizyolojisinin hala tam olarak anlaşılamadığını bildiren Bastaki ve arkadaşları (17), normal ratlara göre diyabetik ratlardaki pariyetal hücrelerin düzensiz dağılım gösterdiğini ve ayrıca diyabetik ratların normal ratlara göre pariyetal hücrelerindeki asit salgısının azaldığını belirtmişlerdir. Bizim yaptığımız çalışmada ise farelerin fundusunda gruplar arasında histolojik açıdan herhangi bir değişiklik tespit edilmemiştir.

Ayrıca yapılan literatür taramalarında (24-26), değişik dokularda kan damarı endotel hücrelerinde HGF'nin yoğun immunoreaktivitesi belirlendiği bildirilmiştir. Çalışmamızda da bu araştırmalara paralel olarak endotel hücrelerinde yoğun HGF immunoreaktivitesi belirlendi. Diyabetik farelerde diğer gruplara kıyasla pariyetal hücrelerde az yoğun HGF immunoreaktivitesi görüldü. Prensipal hücrelerde ise kontrol ve sham grubunda yer yer immunoreaktivite belirlenirken, deneme grubunda HGF immunoreaktivitesine rastlanmadı.

Yapılan çalışmalarda diyabetin fundus bölgesindeki pariyetal hücrelerde düzensiz dağılıma yol açtığı bildirilmiştir (17). Çalışmamızda ise diyabetin pariyetal hücrelerde HGF immunoreaktivitesini düşürdüğü belirlendi. $\mathrm{Bu}$ bulguların sonucunda çalışmamız, diyabetin mide dokusunun fundus bölgesinde HGF immunoreaktivitesini olumsuz yönde etkilediğini göstermektedir.

Sonuç olarak, HGF immunoreaktivitesinin diyabetik farelerde azalmış olması, HGF'nin hücre rejenerasyonunda etkili olması düşünüldüğünde, diyabetin dolaylı olarak fundusdaki hücre yenilenmesini olumsuz yönde etkileyebileceğini düşündürmektedir. HGF, diyabet ve midenin fundus bölgesinin ilişkisini açıklayan immunohistokimyasal bir araştırmaya rastlanmadığı için yaptığımız çalışmanın bu ilişkiyi açıklamasına yardımcı olacağını ve bu alanda yapılacak yeni çalışmalara yardımcı olabileceğini düşünmekteyiz.

\section{Çıkar Çatışması}

Yazarlar, çıkar çatışması olmadığını beyan eder.

\section{KAYNAKLAR}

1. Catchpole B., Ristic JM., Fleeman LM., Davison ᄂ., 2005. Canine Diabetes Mellitus: can old dogs teach us new tricks?. Diabetologia, 48, 19481956.

2. Börset M., Hansen HH., Seidel C., Sundan A., Waage A., 1996. Hepatocyte growth factor and its receptor c-met in multiple myeloma. Blood, 88, 3998-4004.

3. Birchmeier A., Birchmeier W., Gherardi E., Vande Woude GF., 2003. Met, metastasis, motility and more. Nat Rev Mol Cell Biol, 4, 915-925. 
4. You WK., McDonald DM., 2008. The hepatocyte growth factor/c-Met signaling pathway as a therapeutic target to inhibit angiogenesis. BMB Rep, 41, 833-839.

5. Dai C., Li Y., Yang J., Liu Y., 2003. Hepatocyte growth factor preserves beta cells mass and mitigates hyperglycemia in streptozotocin induced diabetic mice. J Biol Chem, 278, 2708027087.

6. Rand JS., Fleeman LM., Farrow HA., Appleton DJ., Lederer R., 2004. Canine and feline diabetes mellitus nature or nuture. J Nutr, 134, 20722080.

7. Reusch CE., Tschour F., Kley S., Boretti S., SieberRuckstuhl N., 2006. Diabetes mellitus in the cat: A Review. Schweiz Arch Tierheilkd, 148, 130-138.

8. Tang YL., Dong XY., Zeng ZG., Feng Z., 2020. Gene expression-based analysis identified NTNG1 and HGF as biomarkers for diabetic kidney disease. Medicine (Baltimore), 99, e18596.

9. Kastelan S., Oreskovic I., Biscan F., Kastelan H., Gverovic Antunica A., 2020. Inflammatory and angiogenic biomarkers in diabetic retinopathy. Biochem Med, 30, 385-399.

10. Fujita Y., Murakami T., Nakamura A., 2021. Recent advances in biomarkers and regenerative medicine for diabetic neuropathy. Int J Mol Sci, 22, 2301.

11. Oliveira AG., Araujo TG., Carvalho BM., Rocha GZ., Santos A., Saad MJA., 2018. The role of hepatocyte growth factor (HGF) in insulin resistance and diabetes. Front Endocrinol (Lausanne), 30, 503.

12. Kanitkar M., Bhonde R., 2004. Existence of islet regenerating factors within the pancreas. Rev Diabet Stud, 1, 185-192.

13. Luna LD., 1968. Manuel of Histologic Staining Methods of the Armed Forces Institute of Pathology. 3rd ed., 38-39, McGraw-Hill Book Company, New York.

14. Hsu SM., Raine L., Fanger H., 1981. Use of avidinbiotin- peroxidase cpmplex (ABC) in immunoperoxidase techniques: a comparison between $A B C$ and unlabeled antibody (PAP) procedures. J Histochem Cytochem, 29, 577-580.

15. Shu S., Ju G., Fan L., 1988. The glucose oxidasedan-nickel in peroxidase histochemistry of the nervous system. Neuroscience Lett, 85, 169-171.

16. Jelodar G., Mohammadi M., Akbari A., Nazifi S., 2020. Cyclohexane extract of walnut leaves improves indices of oxidative stress, total homocysteine and lipids profiles in streptozotocin-induced diabetic rats. Physiol Rep, 8, e14348.

17. Bastaki SMA., Adeghate E., Chandranath IS., Amir N., Tariq S., Hameed RS., Adem A., 2010. Effects of streptozotocin-induced long-term diabetes on parietal cell function and morphology in rats. Mol Cell Biochem, 341, 4350.

18. O'Reilly D., Long RG., 1987. Diabetes and the gastrointestinal tract. Dig Dis Sci, 5, 57-64.

19. Takehara K., Tashima K., Takeuchi K., 1997. Alterations in duodenal bicarbonate secretion and mucosal susceptibility to acid in diabetic rats. Gastroenterology, 112, 418-428.

20. Lin CY., Yeh GH., Hsu FC., Tsai SC., Lau CP., Pu HF., Yu HL., Tung YF., Wang PS., 1991. Gastric acid secretion in streptozotocin-diabetic female rats. Clin J Physiol, 34, 179-186.

21. Baydoun R., Dunbar JC., 1997. Impaired insulin but normal pentagastrin effect on gastric acid secretion in diabetic rats: a role for nitric oxide. Diabetes Res Clin Pract, 38, 1-8.

22. Feldman M., Schiller LR., 1983. Disorders of gastrointestinal motility associated with diabetes mellitus. Ann Intern Med, 98, 378-384.

23. Weber JR., Ryan JC., 1998. Effects on the gut of systemic disease and other extraintestinal conditions. In: Scharschmidt BF, Slei-singer MH, Feldman $M$ (eds) Gastrointestinal and liver disease. WB Saunders Co, Philadelphia, pp: 413416.

24. Grant DS., Kleinman HK., Goldberg ID., Bhargava MM., Nickoloff BJ., Kinsella JL., Polverini P., Rosen EM., 1993. Scatter factor induces blood 
vessel formation in vivo. Proc Natl Acad Sci, 90, 1937-1941.

25. Ono K., Matsumori A., Shioi T., Furukawa Y., Sasayama S., 1997. Enhanced expression of hepatocyte growth factor/c-Met by myocardial ischemia and reperfusion in a rat model. Am
Heart Ass, 95, 2552-2558.

26. Mizuno S., Nakamura T., 2005. Prevention of neutrophil extravasation by hepatocyte growth factor leads to attenuations of tubular apoptosis and renal dysfunction in mouse ischemic kidneys. Am J Pathol, 166, 1895-1905. 